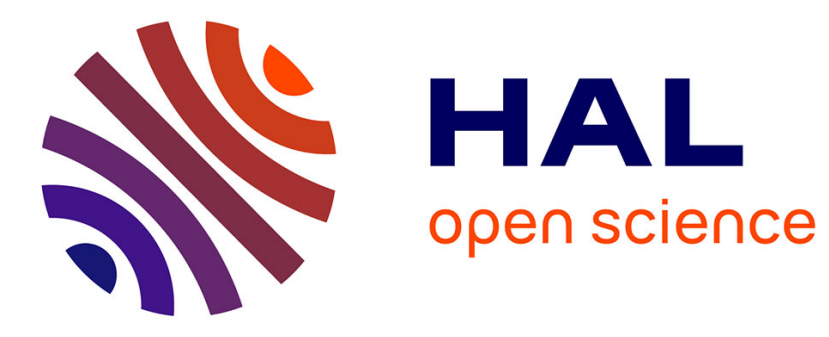

\title{
Simulation methods in the healthcare systems
}

Andrey Khudyakov, Camille Jean, Julie Stal-Le Cardinal, Marija Jankovic, Jean-Claude Bocquet

\section{To cite this version:}

Andrey Khudyakov, Camille Jean, Julie Stal-Le Cardinal, Marija Jankovic, Jean-Claude Bocquet. Simulation methods in the healthcare systems. 4th International Conference on Complex Systems Design and Management - CSD\&M 2013, Dec 2013, Paris, France. pp.141-149. hal-00871615

\section{HAL Id: hal-00871615 https://hal.science/hal-00871615}

Submitted on 1 Sep 2016

HAL is a multi-disciplinary open access archive for the deposit and dissemination of scientific research documents, whether they are published or not. The documents may come from teaching and research institutions in France or abroad, or from public or private research centers.
L'archive ouverte pluridisciplinaire HAL, est destinée au dépôt et à la diffusion de documents scientifiques de niveau recherche, publiés ou non, émanant des établissements d'enseignement et de recherche français ou étrangers, des laboratoires publics ou privés. 


\title{
Simulation Methods in the Healthcare Systems
}

\author{
Andrey Khudyakov ${ }^{1}$, Camille Jean ${ }^{1}$, Julie Stal-Le Cardinal ${ }^{1}$, Marija Jankovic ${ }^{1}$, \\ Jean-Claude Bocquet ${ }^{1}$
}

1École Centrale Paris, Laboratoire Génie Industriel, Châtenay-Malabry, France

Corresponding author: Camille Jean

\begin{abstract}
Healthcare systems can be considered as large-scale complex systems. They need to be well managed in order to create the desired values for its stakeholders as the patients, the medical staff and the industrials working for healthcare. Many simulation methods coming from other sectors have already proved their added value for healthcare. However, based on our experience in the French heath sector (Jean et al. 2012), we found these methods are not widely used in comparison with other areas as manufacturing and logistic. This paper presents a literature review of the healthcare issue and major simulations methods used to address them. This work is design to suggest how more systematic creation of solutions may be performed using complementary methods to resolve a common issue. We believe that this first work can help to better understand the simulation approaches used for health workers, deciders or researchers of any responsibility level.
\end{abstract}

Keywords: System modeling, Systemic tools, Healthcare system 


\section{Introduction}

For governments around the world, the main priority for the success and prosperity of society became support enhancements of the existing healthcare systems (HCS) (WHO, 2000). Statistics suggest that in most countries, a significant fraction of public money is allocated to the healthcare sectors (OECD 2011). Despite these huge investments, HCS have not yet delivered all the expected improvements. While healthcare systems are complex and include many interconnected elements, the rules and heuristics generating managerial decisions are too simplistic to cope with the complexity involved in such systems (Lebcir 2006). The use of model simulation getting wider and wider distributed in the areas of health, but nevertheless not widely used in comparison with other areas, such as manufacturing, logistics and military applications (Sanchez et al. 2000). This paper aims to help health workers, deciders or researchers to understand the relation between the existing modeling approaches and to suggest how more systematic creation of solutions may be performed using complementary methods for the same issue.

Section 2 talks about the general definitions of HCS and briefly describes the nature and goals of HCS. Section 3 contains a review of literature of simulation methods used in HCS and answers the question why modeling approaches is important in this sector. Section 4 provides analyses and results and attempts to set a context for the need of generic framework for HCS which provides guidance for researcher, practitioners, and decision makers interested in utilizing different approaches for healthcare issues.

\section{Context}

\subsection{The Healthcare systems (HCS)}

In this part of the paper, first we describe HCS. Secondly, we define their goals and structure. Thirdly, we briefly establish the existing problems in HCS.

The World Health Organization (WHO) has defined health systems as "the sum of the people, institutions and resources arranged together (in accordance with relevant policies) to maintain and improve the health of the population they serve" (WHO, 2000). A health system consists of all organizations, people and actions whose primary intent is to promote, restore or maintain health

(WHO, 2000). This includes efforts to influence determinants of health as well as more direct health-improving activities. A health system is therefore more than the pyramid of publicly owned facilities that deliver personal health services. It includes, for example, a mother caring for a sick child at home; private providers; behavior change programs; vector-control campaigns; health insurance organizations; occupational health and safety legislation. (WHO, 2007).

The goals of HCS are a good health, responsiveness to the expectations of the population and fair financial contribution (WHO, 2007). But it is also good quality, efficiency, acceptability and equity (Brody 2007).

\subsection{The Healthcare environment}

To understand the use of simulation techniques in HCS we have to understand what the healthcare environment represents and classify the types of existing problems. The key purpose of the framework is the promotion of common understanding of what a health system is and what constitutes health systems strengthening (OECD 2011). These are based on the functions defined in (World health report, 2000). The building blocks are: service 
delivery; health workforce; information; medical products, vaccines and technologies; financing; and leadership and governance (stewardship) (OECD 2011).

The WHO report summarizes the features of health systems oriented to population health and health equity as follows it has defined a single framework of HCS with six building blocks (WHO s. d.):

- Service delivery: It means good health services which deliver effective, safe, quality personal and nonpersonal health interventions to those that need them, when and where needed, with minimum waste of resources;

- Health workforce : it is a well-performing health labor team that works in ways that are responsive, fair and efficient to achieve the best health outcomes possible, given available resources and circumstances (i.e. there are sufficient staff, fairly distributed; they are competent, responsive and productive);

- HCS Information Systems : it is a well-functioning health technology system that ensures the production, analysis, dissemination and use of reliable and timely information on health determinants, health system performance and health status;

- Medical products, vaccines and technologies is a well-functioning health system that ensures equitable access to essential medical products, vaccines and technologies of assured quality, safety, efficacy and cost-effectiveness, and their scientifically sound and cost-effective use;

- Financing : it means a good health financing system that raises adequate funds for healthcare, in ways that ensure people can use needed services, and are protected from financial catastrophe or impoverishment associated with having to pay for them. It provides incentives for providers and users to be efficient;

- Leadership and governance (stewardship) involves ensuring strategic policy frameworks exist and are combined with effective oversight, coalition building, regulation, attention to system-design and accountability.

\subsection{The definition of existing issues in HCS}

In Healthcare system there are both types of problems: complicated problems and complex problems. The complicated problems can be solved in a linear fashion using straightforward, reductionist, repeatable, sequential techniques. They are amenable to traditional project management approaches and they introduce limited/known/manageable consequences and no unintended consequences. A complicated problem is well defined; its solution is clear and can be given to a designer to create detailed specifications and project manager to implement (Robertson-Dunn 2012). Complex problems are problems, whose size, dependence on context, variety of elements and interdependence, make them unable to be fully predictable and therefore controllable. They tend to be non-linear, difficult to understand and their solutions can lead to other problems and unintended consequences. All problems involving new technology, new development environments or new applications should be considered to be complex. This kind of problem cannot be solved by reductionist or sequential approaches but more by using the systemic approach (Le Moigne 1985).

In the previous sections of this chapter the relevance and importance for understanding HCS was established. A deeper discussion of information related to approaches for solving the HCS problems can be found in the literature review in Chapter 3. 


\section{The simulation approaches for HCS}

\subsection{Why simulation is important}

The simulation techniques are now rapidly increasing in HCS modeling (Jun et al. 2009). The simulation can be defined as an imitation of a system. For examples, computer aided design (CAD) systems provide imitations of production facility designs and business process. There is a difference between the concepts of a static simulation, which imitates a system at a point in time, and a dynamic simulation, which imitates a system as it progresses through time (Law 2006). Simulation is the process of designing a model of a real system and conducting experiments with this model for the purpose either of understanding the behavior of the system or of evaluating various strategies (within the limits imposed by a criterion or set of criteria) for the operation of the system (Shannon 1975).

In the following segments we propose the literature review of five existing simulation approaches which have been developed in HCS.

\subsection{The literature review, reliability of existing approaches and those examples studies}

The objectives of this research are to gain insight into approaches and solved issues in HCS, and to suggest how more systematic creation of solutions may be performed in HCS. In the following segments we describe what we found to be five major approaches. We propose the literature review of approaches with their motivations of usage and case applications.

\subsubsection{Markov models}

Markov models are stochastic models (Hidden Markov model; Markov chain; Markov chain Monte Carlo; Markov decision process; partially observable Markov decision process) describing a sequence of possible events in which the probability of each event depends only on the state attained in the previous event. Hospital managers need to make defensible resource allocation decisions driven by hospital inpatient inventory predictions (Broyles et al. 2010). Accurate predictions of hospital inpatient inventory can help evaluate strategic decisions such as policy changes (Marshall et al. 2005). Harper (2002) argues that most existing models of the complex hospital inpatient inventory system are application specific and cannot be generalized to all hospital inpatient inventory systems. Hospital planning and management must consider hospital patient flow for decisions on hospital inpatient staffing and capacity. Hospital inpatient inventory is a "primary driver of resource use in hospitals" and affects demand of many ancillary service including laboratory, pharmacy, physical therapy, radiology, housekeeping, and surgical services (Littig \& Isken 2007). Accurate hourly and daily hospital inpatient inventory prediction is critical to short term hospital operations improvement (Littig \& Isken 2007), staffing costs (Ledersnaider \& Channon 1998), ambulance diversion (Schull et al. 2003), hospital bed management (Mackay, 2001), in the areas of inpatient placement (Clerkin et al.1995). It have been used by (Broyles et al. 2010) in order to decrease the delay on the part of customers waiting for service, for delivery, operating cost reduction, lead time reduction, faster plant changes, capital cost reduction and improved customer service and for not arriving as promised ineffective management of chronic illness (Broyles et al. 2010).

\subsubsection{Discrete-event simulation (DES)}

Discrete Event Simulation (DES) is modeling the operation of a system as a discrete sequence of events over time. Each event occurs at a particular instant in time and marks a change of state in the system (Zeigler et al. 2000). It 
have been used to spread and containment of hospital acquired infections (Hagtvedt et al. 2009); planning for disease outbreaks (Aaby et al. 2006); determining bed requirements (Griffiths et al. 2010); investigating emergency departments (Paul et al. 2010); and determining appropriate ordering policies in the blood supply chain (Katsaliaki \& S. C. Brailsford 2007). It is use for planning, scheduling, reorganization and management of healthcare and hospital services, communicable diseases, bio-terrorism, screening, costs of illness, economic evaluation (comparing alternative healthcare interventions), policy and strategy evaluation (Fone et al. 2003). And also for risk reduction, operating cost reduction, lead time reduction, faster plant changes, capital cost reduction and improved customer service ((Robinson et al. 2012).

\subsubsection{System dynamic modeling (SD)}

System dynamic modeling (SD) is an approach to understanding the behavior of complex systems over time. It deals with internal feedback loops and time delays that affect the behavior of the entire system. It is described as an analytical modeling approach whose roots could be said to lie in the general systems theory approach (Bertalanffy 1993). System dynamics is a computer-based simulation modeling methodology developed at the Massachusetts Institute of Technology (MIT) in the 1950s by Jay Forrester as a tool for managers to analyze complex problems (Forrester 1999). The word "dynamic" implies continuous change and that is what dynamic systems do - they continuously change over time. Their position, or state, is not the same today as it was yesterday and tomorrow it would have changed yet again. Using system dynamics simulations allows us to see not just events, but also patterns of behavior over time. Sometimes the simulation looks backward, to historical results. At other times it looks forward into the future, to predict possible future results. Understanding patterns of behavior, instead of focusing on day-to-day events, can offer a radical change in perspective. It shows how a system's own structure is the cause of its successes and failures. This structure is represented by a series of causally linked relationships. The implication is that decisions made within an organization have consequences, some of which are intentional and some are not. Some of these consequences will be seen immediately while others might not be seen for several years. System dynamics simulations are good at communicating not just what might happen, but also why. This is because system dynamics simulations are designed to correspond to what is, or might be happening, in the real world. As example, we can cited the work about long waiting lists (Siciliani 2006); ineffective management of chronic illness epidemics of obesity; heart disease (Jones \& Homer 2006) and decision-making in resources allocation for telehealth (Jean et al. 2012).

\subsubsection{SD+}

SD+, Brailsford describe it as a form of mixing methodologies of SD and DES and due to fundamental differences, mixing methodologies is quite challenging (S. Brailsford 2008). There are problems which exhibit elements which require both SD and DES, and there are interactions between them. In those scenarios accurate analysis demands to capture those interactions. It has been argued

in literature SD-, where SD and DES are integrated symbiotically, will provide more insight and accurate analysis of such problems with fewer assumptions (Chahal et al. 2013). Also for them this it means that the same thing has been represented in both models but this representation does not have same face value. Mostly SD represents the aggregated version of the variable which is disaggregated in DES and can be represented in DES either by single or group of variables which holds value equivalent to SD variable. It has the potential to provide a more complete way of dealing with the complexity of the real world (Chahal et al. 2013).. 


\subsubsection{Agent-based approach \& Multi-agent systems}

Agent-based approach \& Multi-agent systems is presented, aiming to minimize the waiting time of patient as well as the cost of care within emergency department (Daknou et al. 2008). Artificial Intelligence and knowledge based systems are assuming an increasingly important role in medicine for assisting clinical staff in making decisions under uncertainty (e.g. diagnosis decisions, therapy and test selection, and drug prescribing (Huang et al. 1995). In France (Daknou et al. 2008) were successfully adopted the software agents to provide the means to accomplish such real-time application for taking care of all arrival patients at the emergency department and to improve the quality of care.

\section{Analysis approaches in relation to the problematic element}

In this part of the analysis we propose to look into the relation between the different approaches and the problem element(s). The development activities and perspective of simulation techniques is now rapidly increasing in healthcare systems modeling ((Barnes et al. 1997; Jun et al. 2009). We understood that usually for the more realistic picture in complex issues, as in HCS issues, it cannot be used just one of the approach, very often it have to be mixed. For example, for right medical decision making and making decisions under uncertainty we can use agent-base approach or multi-based approach. To simulate the existing system, it is appropriate to use the Markov chain, for simulation the system over time, the interaction between the elements of system and understanding of avocation in relation to the element of problem complexity it is better to use SD, DES or (SD+).

\begin{tabular}{|c|c|c|c|c|c|}
\hline Decision Level & Markov Model & $\begin{array}{c}\text { System dynamic } \\
\text { modelling }\end{array}$ & $\begin{array}{c}\text { Discrete event } \\
\text { simulation (DES) }\end{array}$ & SD+ & $\begin{array}{c}\text { Agent-based } \\
\text { approach }\end{array}$ \\
\hline Short term decision & 1 & & & & 1 \\
\hline Mid term decision & 1 & & 1 & & 1 \\
\hline Long term decision & & 1 & 1 & 1 & \\
\hline
\end{tabular}

Table 1: Decision Level

Also, it is necessary to look into the effectiveness of methods in making the best solutions (decisions) in time. The table 1 describes and classifies these decisions according to the classical operations of decision framework, which would consist of three levels: short-term decisions; mid-term decisions; long-term decisions. Short-term decisions: would consist of one or several determination of process, rules, short planning staff, use of equipment, human resources. Mid-term decisions: would consist to reorganization or optimization of allocation of resources, human resources or staff in fix (known) location. Long term decisions: would consist of one or several objectives of modeling, human resources, medical equipment, as well as the identification of new location (allocation of resources), bases regions, capacity of system.

\section{Conclusion}

In this paper we have attempted to set a context for the need of generic framework for HCS which provides guidance to the prospective researcher, practitioners, decision makers interested in utilizing different approaches for healthcare system issues. Research project focused on approaches to solve one of problems developed in the context of HCS. HCS problems are understood as any problems that has mainly based in HCS. Based on the 
literature it was recognized that generic framework should be capable of providing guidance to prospective users with regards to mapping between different approaches.

It has been argued in literature that the investment and effort involved in development of integrated "hybrid modeling" (decision making method which includes both qualitative and quantitative techniques; using two or several approaches for the same problem) is wasted if the problem does not require "hybrid modeling". It is expected that this work will encourage those engaged in simulation and modeling (e.g., researchers, practitioners, decision makers) to realize the potential of cross-fertilization of the several modeling approaches.

\section{References}

Aaby, K. et al., 2006. Montgomery County's Public Health Service Uses Operations Research to Plan Emergency Mass Dispensing and Vaccination Clinics. Interfaces, 36(6), p.569-579.

Barnes, C.D. et al., 1997. Success Stories In Simulation In Health Care. In Simulation Conference, 1997., Proceedings of the 1997 Winter. Simulation Conference, 1997., Proceedings of the 1997 Winter. p. 1280-1285. Bertalanffy, L. von, 1993. Théorie générale des systèmes, Dunod.

Brailsford, S., 2008. System dynamics : What's in it for healthcare simulation modelers. In Proceedings of the 2008 Winter Simulation Conference. p. 1478-1483.

Brody, W., 2007. What's Promised Waht's Possible?

Broyles, J.R., Cochran, J.K. \& Montgomery, D.C., 2010. A statistical Markov chain approximation of transient hospital inpatient inventory. European Journal of Operational Research, 207(3), p.1645-1657.

Chahal, K., Eldabi, T. \& Young, T., 2013. A conceptual framework for hybrid system dynamics and discrete event simulation for healthcare. Journal of Enterprise Information Management, 26(1/2), p.50-74.

Daknou, A. et al., 2008. Agent based optimization and management of healthcare processes at the emergency department. International Journal of Mathematics and computers simulation, 2(3), p.285-294.

Fone, D. et al., 2003. Systematic review of the use and value of computer simulation modelling in population health and health care delivery. Journal of Public Health, 25(4), p.325-335.

Forrester, J.W., 1999. Industrial dynamics, Pegasus Communications.

Griffiths, J.D. et al., 2010. A simulation model of bed-occupancy in a critical care unit. Journal of Simulation, 4(1), p.52-59.

Hagtvedt, R. et al., 2009. A Simulation Model to Compare Strategies for the Reduction of Health-Care-Associated Infections. Interfaces, 39(3), p.256-270.

Huang, J., Jennings, N.R. \& Fox, J., 1995. Agent-Based Approach to Health Care Management. Applied Artificial Intelligence, 9(4), p.401-420.

Jean, C. et al., 2012. Telehealth: towards a global industrial engineering framework based on value creation for healthcare systems design. In Proceedings of the 12th International Design Conference DESIGN 2012. DESIGN 2012. p. 949-958. Available at: http://hal.archives-ouvertes.fr/hal-00714273 [Consulté le juillet 3, 2012]. 
Jones \& Homer, 2006. Understanding Diabetes Population Dynamics Through Simulation Modeling and Experimentation. American Journal of Public Health.

Jun, G.T. et al., 2009. Health care process modelling: which method when? International Journal for Quality in Health Care, 21(3), p.214-224.

Katsaliaki, K. \& Brailsford, S.C., 2007. Using Simulation to Improve the Blood Supply Chain. Journal of the Operational Research Society, 58(2), p.219-227.

Law, A., 2006. Simulation Modeling and Analysis with Expertfit Software $4^{e}$ éd., McGraw-Hill Science/Engineering/Math.

Lebcir, R., 2006. Health Care Management: The Contribution of Systems Thinking, University of Hertfordshire. Ledersnaider, D.L. \& Channon, B.S., 1998. SDM95--reducing aggregate care team costs through optimal patient placement. The Journal of nursing administration, 28(10), p.48-54.

Littig, S.J. \& Isken, M.W., 2007. Short term hospital occupancy prediction. Health Care Management Science, 10(1), p.47-66.

Marshall, A., Vasilakis, C. \& El-Darzi, E., 2005. Length of Stay-Based Patient Flow Models: Recent Developments and Future Directions. Health Care Management Science, 8(3), p.213-220.

Le Moigne, J.-L.L., 1985. La théorie du système général, Presses Universitaires de France (PUF).

OECD, 2011. Health at a Glance, OECD Indicators,

OMS (World Health Organisation), 2000. Rapport sur la santé dans le monde, 2000 - Pour un système de santé plus performant, Available at: http://www.who.int/whr/2000/en/whr00_fr.pdf.

Paul, S.A., Reddy, M.C. \& Deflitch, C.J., 2010. A Systematic Review of Simulation Studies Investigating Emergency Department Overcrowding. Simulation, 86(8-9), p.559-571.

Robertson-Dunn, B., 2012. Beyond the Zachman Framework: Problem-oriented System Architecture. Available at: http://www.academia.edu/1863616/Beyond_the_Zachman_Framework_Problem-

oriented_System_Architecture [Consulté le avril 20,2013].

Robinson, S. et al., 2012. SimLean: Utilising simulation in the implementation of lean in healthcare. European Journal of Operational Research, 219(1), p.188-197.

Sanchez, S.M. et al., 2000. Emerging issues in healthcare simulation. In Simulation Conference, 2000.

Proceedings. Winter. Simulation Conference, 2000. Proceedings. Winter. p. 1999-2003.

Schull, M.J. et al., 2003. Emergency department overcrowding and ambulance transport delays for patients with chest pain. Canadian Medical Association Journal, 168(3), p.277-283.

Shannon, R.E., 1975. Systems simulation: the art and science, Prentice-Hall.

Siciliani, L., 2006. A dynamic model of supply of elective surgery in the presence of waiting times and waiting lists. Journal of Health Economics, 25(5), p.891-907.

WHO, 2007. Everybody business : strengthening health systems to improve health outcomes, 
Zeigler, B.P., Kim, T.G. \& Praehofer, H., 2000. Theory of Modeling and Simulation: Integrating Discrete Event and Continuous Complex Dynamic Systems 2nd Edition., Academic Press Inc. 